April - 2003

\title{
Indicators of Support in Online Interaction
}

\author{
Patrick J. Fahy \\ Athabasca University - Canada's Open University
}

\begin{abstract}
Peer-to-peer interaction using computer-mediated communication (CMC) would appear to be a promising source of timely and cost-effective student support, but little empirical evidence regarding actual participant support behaviour has been presented (Lee, 2000). This paper reports a study of the occurrence of 13 online strategies defined as "supportive," according to the categorizations found in an instrument called the Transcript Analysis Tool (TAT). The corpus used in the study consisted of three transcripts produced by students (graduate degree and professional development diploma candidates) engaged in course-related CMC conferencing. Analysis of the transcripts generated by the three groups showed the following:
\end{abstract}

- The support strategies most frequently used by the three groups were referential statements (statements which made reference to others' previous comments; TAT type 2B), signatures, greetings, and horizontal questions (open-ended questions which invited negotiation of a plausible answer; TAT type 1B).

- There was some variability among the groups in the frequency of use of referential statements, horizontal questions, emoticons, and invitations to others.

- High- and low-support groups differed from each other in their use of referential statements, signatures, greetings, horizontal questions, rhetorical questions, and humour.

As an examination of the social element of three communities of inquiry, the study described how members of these groups attempted to connect with one another interpersonally, using asynchronous conferencing, on topics related to the conceptual content of the courses. The paper concludes that while in this case the above behaviours were the means most often used to support and encourage interaction, further examination of online support behaviours and strategies is needed, especially in relation to valued outcomes such as persistence, greater motivation, less stress, and, ultimately, enhanced learning.

\section{Introduction}

Interpersonal growth of participants and promotion of intellectual development have for some time been regarded as important challenges in distance education, particularly as problems of dissemination of materials and other logistical issues have largely been resolved, at least in developed countries (Commonwealth of Learning, 1993). The emerging view of student services in education is one of an integrated and coordinated institutional response to the range of possible 
Fahy Indicators of Support in Online Interaction

learner needs, which promotes successful and satisfying program completion and seamlessly combines counselling and advising with more traditional instructional services (Simpson, 2000; Allen, 2002). Within an environment of critical and reflective personal and group activities the resulting "community of inquiry" should support both cognitive and social engagement (Garrison, 2002).

One of the obvious but largely un-addressed questions arising from increased use of interactive communications technologies is whether course-related online communications can be shown to contain "supportive" elements; that is, whether, to what degree, and how do participants use the interactive possibilities of online technologies to give and receive support? (McInnis and Brindley, 1986; Juler, 1990; Carrier, 1991; Cannell, 1999; Saltiel and Russo, 2001) There is increasing use of technology in online programs to provide routine information or to permit students to request clarification on assignments and course content (Johnson, 2001), and an increasing array of administrative tasks can be accomplished online (Luedtke, 2000). But little empirical data exist on the forms and amounts of actual peer-to-peer student support behaviour online (Lee, 2000), despite recognition of this form of social support as an important type of "relational cultural capital" (Carnwell and Harrington, 2001), an "enabling” resource for learning (Rezabek, 2002), and a significant enhancement to the intellectual quality of learning environments (Garrison, 2002).

The reason for the lack of attention to the ways in which online interaction is actually used for support purposes may be due to the newness and rapid evolution of the online technologies on which it is based. Nevertheless, possibly useful evidence has been emerging about the strategies participants use to interact within text-based online communities (Fahy, Crawford and Ally, 2001; Garrison, Anderson and Archer, 2001). Analyses of online conferences have yielded information about how participants view each other, and how they collaboratively create and sustain purposeful interaction, which might be related to other findings on decision support systems, the workings of task groups, strategic management teams, cognitive presence/ metacognition, and how individuals connect and collaborate interpersonally in online learning environments (Stringer and Uchenick, 1986; DeSanctis and Gallupe, 1987; Walther, 1996; Garrison, 2002). From these sources it appears possible that the same tools and techniques, which enable participants to solve procedural or logistic problems, may also be adapted to enhance interpersonal online relationships (Tait, 2000). The same analytic approaches may also be applicable. If this premise is accepted, a logical next step is to use tools that focus on the actual interaction patterns found in transcripts to examine whether and how participants respond to others' needs for intellectual, social and interpersonal support.

\section{Literature Review}

\section{The Concept of Support}

Student support has for some time been viewed as consisting of all those interventions and facilities that help distance learners cope with the technology, isolation and communication problems they might encounter (Tobin, 1995). In this view, interpersonal interaction may be regarded as a basic type of learner support, regardless of its source, intervening or enabling media, or formal/ informal status. What is critical is that supportive interventions be "personalised and localised" (Tait, 1996), as in learning communities of various kinds that address "fundamental human needs for social interaction in the educational context" (p. 12). 
Fahy Indicators of Support in Online Interaction

Another basic principle is the provision of a variety of personal and individual human contacts to counter the mass-produced nature of many distance education materials (Robertshaw, 2000), and to recognize the personal and public-social character of education (Garrison, 2002). Sewart (1993) argued a decade ago that without individualized and varied support systems and components, modern distance education might be seen as too "industrialized" and, consequently, depersonalized (p. 122). In this view, individualized treatment through student support subsystems is essential to learner success, especially as institutions grow in size and complexity (p. 128). Sewart concluded that support must acknowledge and respond to the "almost infinite" needs and differences of its clients (p. 129), a requirement which, before the arrival of effective and ubiquitous communications technologies, was a truly daunting prospect indeed.

Personalization and individualization of learning support are enhanced in the provision of choices and emphasis on cooperation, connection, collaboration and interaction (replacing competition) in the learning environment and its relationships (Carrier and Schofield, 1991; Commonwealth of Learning, 1993; Allen, 2002; Garrison, 2002). Technologies may be helpful in facilitating these support objectives. When online moderators and instructors accept responsibility for student support, instruction and support functions begin to blend and overlap, ideally forming a web of seamless resources and options available to learners in any kind of need (Simpson, 2000).

\section{Interaction and Peer-To-Peer Support}

The blending of instruction and support potentially benefits both, especially if instructors encourage students to engage in mutually supportive collaborative interactions. While the exact nature of those interactions may vary (this study explored some of them), there are principles which could be helpful in using CMC-based interactions in helpful ways:

- The instructor does not always have to be the primary source of all student support; technology-mediated peer-to-peer support can be a valuable adjunct to the formal support most institutions and programs are able to provide, and when programs become large or lose flexibility for any reason, they may substitute such support (Brown and Brown, 1994).

- The design of instructional materials or texts which anticipate all student questions and needs is probably not feasible (Juler, 1990); it is therefore preferable to provide an environment where questions can be posed and information can be discussed freely in a timely and flexible manner as needed.

- The process of peer interaction presents students with possible new roles; in addition, the "unstructured and unpredictable" nature of the resulting discourse may be desirable from a learning perspective (Juler, 1990).

- The interaction among peers common in CMC has constructivist aspects, producing an environment in which critical discourse and transactional and transformational learning co-reside in an atmosphere emphasizing consensusbuilding, collaboration and cooperation (Commonwealth of Learning, 1993; Garrison, 2002).

To summarize, technology-based interaction, especially peer-to-peer, because it is readily available and increasingly familiar, may constitute a valuable source of support, and under some distance education circumstances might even be viewed as essential for a full and successful 
Fahy Indicators of Support in Online Interaction

(reflective and collaborative) learning experience, supporting two long-acknowledged goals of distance education, learning and socialization (Mugridge and Kaufman, 1986). As robust communications systems have become more widely available and familiar, the question arises as to whether and how peers use such tools to interact with and to support one another. Does examination of online interaction show that participants attend to one another, use the strategies available to enhance personal, social and cognitive development, and thus strive to create a community of inquiry, socially and cognitively attentive to the individual needs of participants? (Purnell, Cuskelly and Danaher, 1996; Garrison, Anderson and Archer, 2000, 2001)

\section{The Study}

\section{Background}

Previous exploratory work in analysis of the structures and interaction patterns in CMC transcripts, using a tool call the TAT (Transcript Analysis Tool), revealed interaction patterns useful in assessing different communications styles and online behavioural preferences among participants. Methodologically, this work also demonstrated that both structural and notional (content) elements of transcripts could reveal subtleties in resulting communication and social networking patterns.

The TAT consists of the following categories (Attachment A):

- $\mathbf{1 A}$ - vertical questions: assume a correct answer exists and can be found

- 1B - horizontal questions: invite negotiation on a plausible answer

- 2A - non-referential statements: make no reference to others' comments or views

- 2B - referential statements: make direct or indirect reference to others' statements

- 3 - reflections: usually guarded personal thoughts, judgments, opinions or experiences

- 4 - scaffolding and engaging: intended to initiate, continue, encourage or acknowledge interaction, and to "warm" or personalize the interaction environment

- 5A - quotations and paraphrases: from sources within or outside the conference

- $\mathbf{5 B}$ - citations: attributions of quoted or paraphrased material

In previous work with a smaller transcript corpus (the Centre for Distance Education (CDE) option course in this study), comparisons of the frequencies and proportions of the above sentence types found in the transcript (along with structural cues captured or generated by synchronous conferencing software, such as the date and time of posting, the sequence of postings, and interaction patterns among specific participants), produced a multi-layered description of conference interaction. This corpus and technique have been used subsequently to examine the presence of expository and epistolary communications (Fahy, 2002b), patterns in the use of qualifiers and intensifiers (Fahy, 2002a), and aspects of cognitive presence itself (Fahy, 2002c).

In this study, sentences which denoted "supportive" behaviour (those coded as TAT types: 1B, horizontal questions; 2B, referential statements; and 4, scaffolding and engaging comments) in 
three study transcripts, were examined. The supportive nature of these categories was found in the characteristics of the attendant communication, as described below (Fahy, et al., 2001):

Horizontal questions (Type 1B) are those for which there is no one right answer, others are invited to help provide plausible or alternate "answers," or to help shed light on the question. The interactive process itself helps build and articulate consensus toward an adequate (as opposed to a correct) answer.

Referential statements (Type 2B) include direct answers to questions, or comments referring to specific preceding statements (by other participants). Referential statements suggest a dialogue, or interplay of statements, questions and responses, related to others.

Scaffolding and engaging comments (TAT 4) are specifically intended to initiate, continue or acknowledge interpersonal interaction, and to "warm" and personalize the discussion by greeting, welcoming and recognizing others. These comments connect or agree with, thank or otherwise acknowledge someone else and recognize the helpfulness and legitimacy of the ideas, comments, capabilities, and experience of others. Included are comments without real substantive meaning, "phatics," which signify the speaker/ writer's readiness for interaction (Feenberg, 1989), greetings, and [n]etiquette-related devices such as closings and signatures, rhetorical questions (which gently suggest a position, while leaving open the possibility of further discussion about it), and emoticons.

A total of 13 supportive behaviours coded in one of the three TAT categories were identified. The view in this study was that, because of their interpersonal and social focus and impact, these 13 strategies or "moves" (Herring, 1996) operationally constituted a construct of "support," the presence of which had the effect of motivating others to become or remain engaged in the online interaction (Attachment B):

1. Type 1B: Horizontal questions

2. Type 2B: Referential statements

Type 4: Scaffolding and engaging comments:

3. Acknowledgements

4. Agreements

5. Apologies

6. Closings

7. Emoticons

8. Humour

9. Invitations

10. Rhetorical questions

11. Salutations

12. Signatures

13. Thanks

The above construct of "online support" includes the linguistic, paralinguistic and graphic devices which, if they chose to do so, CMC users might use to signal their recognition and support of others as co-participants in the online community. These devices and strategies are supportive of communication, replacing myriad analogous sociolinguistic devices and strategies, including nonverbal elements normally available in face-to-face interaction, (Ridley and Avery, 1979). In face- 
Fahy Indicators of Support in Online Interaction

to-face discourse, conventions exist for participants to check responses and avoid miscommunication; in online situations, the conventions necessary for productive and positive interaction usually must be adapted or invented, an unavoidable step in the adoption of any complex innovation (Buderi, 1996). Extra care is needed to reduce online communication failures, as the channels for confirmation are less responsive and more subject to misinterpretation (Feenberg, 1989; Burge, 2000), and the consequences for miscommunication in the network can be severe.

For participants in online interaction, the process is one of adapting established and well understood face-to-face communications conventions and strategies to fit new media and, in the case of CMC, the constraints of asynchronicity. This study was intended to determine whether, how often, and in what ways, online participants interacting asynchronously using text only, might employ any of the 13 identified support conventions, permitting an estimate of the construct "support" in these conferences.

\section{Method}

The CMC participants whose interaction generated the study transcript were students and instructors in three courses, two consisting of graduate students from Athabasca University's Centre for Distance Education (CDE), and one from a diploma program offered by a non-degree granting Alberta post-secondary institution $(n=17)$. The CDE courses included one core course required of all MDE students $(n=26)$, and one senior option (elective) course $(n=13)$. In all three cases, the discussions which produced the study transcripts, were moderated by the course instructor, who also participated in the discussion.

CMC played a somewhat different role in the three courses. In the CDE courses, credit was awarded for participation: 10 per cent of the course final mark was dependent upon CMC participation in the option course, 15 per cent in the core course. The non-AU course, which was non-credit professional development training, did not award marks for CMC participation. The CDE courses were 13 weeks in length, while the non-CDE course was three weeks long. Most students in all three groups held Bachelor's degrees (10 per cent held graduate degrees), most were teachers/ trainers, and all were experienced technology users.

Coding and analysis of transcript content were accomplished using ATLAS.ti, a qualitative analysis software tool, and SPSS-PC. The CDE option course transcript was coded by the author, while the CDE core course and the non-CDE course transcripts were coded by CDE research assistants (RAs) who were trained by the author. Coding was at the sentence level, and multiple codes were used for sentences that contained more than one category. The RAs worked in pairs, checking each other's codings and, where necessary, discussing and resolving coding disagreements. Where coding disagreements or questions arose for any reason the author served as the arbiter. The author also performed all analyses reported here using ATLAS.ti and SPSSPC.

\section{Findings}

\section{Group Conference Activity Levels and Behaviour}

Tables 1 and 4 compare of some descriptors of overall conference activity by gender and by course. The small differences in Table 1 (none of which were statistically significant) showed 
Fahy Indicators of Support in Online Interaction

little variation in interaction, but a small difference in the support ratio (total supportive postings divided by total posts) favouring women, showed a finding consistent with previous reports (Fahy, 2002b). The fact that men appeared to post more frequently than did the women was influenced by the fact that three-quarters of the students enrolled in the non-CDE course, which was three weeks long and consequently provided fewer conferencing opportunities, were women (Table 4). The largest group was the CDE core class $(n=26)$, but the largest transcript and the greatest number of postings were produced by the CDE option course. The ratio of the support score (the sum for each individual of all sentences which were coded as one of the 13 support types listed above) to total posts did not differ among the groups, indicating that despite differences in interaction opportunities and volume, the participants in the three groups engaged in proportionally much the same kinds of supportive behaviours.

Table 1. Conference participation, support score, and support ratio, by gender

\begin{tabular}{|l|c|c|c|c|c|c|}
\hline Element & \multicolumn{2}{|c|}{ Males } & \multicolumn{2}{c|}{ Females } & \multicolumn{2}{c|}{ Total } \\
\hline & Mean & S.D. & Mean & S.D. & Mean & S.D. \\
\hline Total posts & 15.61 & 11.48 & 12.67 & 10.65 & 13.87 & 10.99 \\
\hline Support score & 37.96 & 33.79 & 36.30 & 27.73 & 36.98 & 30.01 \\
\hline $\begin{array}{l}\text { Support ratio (support score/ total } \\
\text { posts) }\end{array}$ & 2.37 & 1.22 & 3.14 & 1.65 & 2.82 & 1.53 \\
\hline
\end{tabular}

"Sum of all sentences coded in TAT categories 1B (horizontal questions), 2B (referential statements), and 4 (scaffolding and engaging comments).

\section{Supportive Activity}

Table 5 (Attachment C) shows the overall presence of TAT categories in the three transcripts. As in a previous study (Fahy, et al., 2001), the most common category was non-referential statements (type 2A; 54.6 per cent), followed distantly by scaffolding and engaging comments (type 4; 15.2 per cent) and reflections (type 3; 11.3 per cent).

Table 2 shows a comparison of the three groups in relation to the 13 support behaviours of interest. The first observation was in relation to the differences in the occurrence of each of the 13 support indicators. The table shows the proportion of each of the indicators within the total of "support" elements for each group.

Table 2. Percentage of support indicators as part of supportive posts only, by course

\begin{tabular}{|l|c|c|c|c|c|}
\hline & \multicolumn{2}{|c|}{ Mean } & \multicolumn{2}{c|}{ S.D. } & Sig. $^{*}$ \\
\hline Support indicators & $\begin{array}{c}\text { High } \\
\text { Support } \\
(\mathrm{n}=17)\end{array}$ & $\begin{array}{c}\text { Low } \\
\text { Support } \\
(\mathrm{n}=13)\end{array}$ & $\begin{array}{c}\text { High } \\
\text { Support }\end{array}$ & $\begin{array}{c}\text { Low } \\
\text { Support }\end{array}$ & \\
\hline Greetings & .51 & .15 & .29 & .22 & .001 \\
\hline Humour & .02 & .00 & .03 & .00 & .011 \\
\hline Rhetorical questions & .14 & .02 & .15 & .09 & .013 \\
\hline Signatures & .63 & .26 & .41 & .33 & .010 \\
\hline Horizontal questions (1B) & .32 & .13 & .24 & .23 & .035 \\
\hline Referential statements (2B) & .83 & .41 & .31 & .34 & .002 \\
\hline
\end{tabular}

t-test.

By a wide margin, the chief support indicators found in all course transcripts were: 
Fahy Indicators of Support in Online Interaction

- Referential statements (TAT type 2B): these constituted 26.7 per cent of all support indicators overall in the three groups, with a significant range in variation (from a low of 20 per cent in the CDE core course, to a high of 38 per cent in the CDE option course).

- $\quad$ Signatures: these comprised 16.4 per cent of all support strategies, with a small range (less than 6 per cent) among the three groups.

- Greetings: made up 13.3 per cent of all support, with a range among the three groups of less than 5 per cent.

- Horizontal questions (TAT type 1B): while these totalled almost 10 per cent of all supportive postings, the difference in means among the three groups was significant, at over 12 per cent. (The CDE core course transcript contained a substantially higher proportion of horizontal questions than either of the other two.)

In total, the four indicators above accounted for two-thirds of all supportive behaviour found in the transcripts. A fifth observed difference, in expressions of thanks, approached significance ( $p=$ .074), with the non-CDE course, despite its smaller size, containing a proportion of thanks occurrences over four times greater than was found in the CDE option course (5.3 per cent and 1.3 per cent, respectively).

Another finding was that the participants' support scores varied widely, reflecting differences on an individual level in terms of the amount of supportive online behaviour exhibited. The overall mean support score for the total group was 41 (S.D. = 35.1); the range was 149 (minimum = 0 , maximum $=149$ ).

Within-group gender differences were significant on only one element: agreement. Women in both the CDE option course and in the non-CDE course were more likely to express agreement than the men. As noted earlier, this finding is consistent with other reports (Herring, 1996; Fahy, 2002b).

Five other between-group differences were found (Table 6, Attachment C):

- The non-CDE course contained proportionally more acknowledgements, use of emoticons, and more occurrences of thanks than one or the other of the other two groups. (In regard to acknowledgements, the non-CDE course instructor modeled this behaviour, employing acknowledgements 20 times in her postings, 13 per cent of her supportive elements overall. In comparison, the CDE option and the CDE core instructors employed acknowledgements 0 and 4 times, respectively.)

- The CDE core course contained proportionally more greetings and horizontal questions. (The modeling here was negative: the CDE core course instructor used fewer horizontal questions [12] than did the CDE option instructor [46] or the non-CDE instructor [13].)

Table 2 also shows that use of four support strategies varied among the three groups: referential statements, horizontal questions, use of emoticons, and invitations. These variations need further examination; they may indicate behaviours, which vary with different group purposes, 
Fahy Indicators of Support in Online Interaction

individuals, or moderating behaviour, or they may be nothing more than chance fluctuations. If they do identify strategies that actually increase support, they also constitute behaviours, which might be readily focused on or modeled if a more supportive online environment is desired.

In order to identify more clearly which of the individual behaviours were most associated with levels of overall supportive behaviour, the online activities of high- and low-support individuals (the top and bottom quartiles) were examined. Thirty individuals were included in the two groups, 13 in the lowest quartile (those whose support score, the sum of all their "supportive" postings, totalled 16.25 or less) and 17 in the highest (support score 41 or above). (The between-group difference in overall support scores, 3.22 and 1.71 respectively, for the high- and low-support groups, were significant at the .001 level.)

The comparison of these two groups' use of the 13 support behaviours revealed differences on the six items shown in Table 3. Participants who have high support values tend to engage in strategies of greetings, humour, rhetorical questions, signatures, horizontal questions, and referential statements.

Table 3. Differences between High-Support and Low-Support groups based on support scores

\begin{tabular}{|l|c|c|c|c|c|}
\hline Support indicators & $\begin{array}{c}\mathrm{CDE} \\
\text { option } \\
(\mathrm{n}=13)\end{array}$ & $\begin{array}{c}\mathrm{CDE} \\
\text { core } \\
(\mathrm{n}=25)\end{array}$ & $\begin{array}{c}\text { Non- } \\
\mathrm{CDE} \\
(\mathrm{n}=17)\end{array}$ & $\begin{array}{c}\text { Total } \\
(\mathrm{n}=55)\end{array}$ & Sig. $^{*}$ \\
\hline $\begin{array}{l}\text { 2B: Referential } \\
\text { statements }\end{array}$ & $38.0 \%$ & $20.2 \%$ & $27.7 \%$ & $26.7 \%$ & .011 \\
\hline Signatures & 20.2 & 16.3 & 13.7 & 16.4 & .394 \\
\hline Greetings & 10.9 & 15.8 & 11.6 & 13.3 & .156 \\
\hline 1B: Horizontal questions & 6.3 & 15.9 & 3.5 & 9.8 & .000 \\
\hline Acknowledgements & 6.0 & 6.3 & 11.9 & 8.0 & .195 \\
\hline Agreements & 4.7 & 7.8 & 5.9 & 6.5 & .609 \\
\hline Rhetorical questions & 4.5 & 3.2 & 5.8 & 4.3 & .665 \\
\hline Closings & 1.4 & 4.7 & 4.3 & 3.8 & .270 \\
\hline Thanks & 1.3 & 2.8 & 5.3 & 3.2 & .074 \\
\hline Emoticons & 2.4 & 1.0 & 3.8 & 2.2 & .045 \\
\hline Invitations & 1.1 & 3.6 & 0.9 & 2.2 & .029 \\
\hline Apologies & 1.3 & 0.8 & 3.8 & 1.8 & .387 \\
\hline Uses of humour & 1.9 & 1.7 & 2.0 & 1.8 & .964 \\
\hline Total & $100 \%$ & $100 \%$ & $100 \%$ & $100 \%$ & \\
\hline
\end{tabular}

\section{Discussion}

"Support" in distance learning may be constrained by the separation of the participants (Moore, 1991). However, there is no simple association between distance and the perception of separation or isolation. Indeed, face-to-face interaction may also suffer from various "distances" (psychological, interpersonal, cultural, linguistic, environmental, etc.), while anyone who has ever had a pen pal, or been caught up in an online relationship, knows the power of "mere" asynchronous text to create and sustain interpersonal engagement.

The purpose of this research was to determine whether and how peers used online strategies to lessen interpersonal distance and increase interpersonal interaction, as compared with strategies that simply state a position, convey information, or answer or ask factual questions. While the study analyzed online behaviour only, it is recognized that the true test of any strategy is the impact of "supportive" online behaviour on other efficacy outcomes, such as persistence, 
Fahy Indicators of Support in Online Interaction

satisfaction, and learning. The connection of these outcomes to the analytic model and assumptions used here needs further investigation.

At the same time, this analysis is valuable because it describes "natural" online interaction behaviour. Support strategies vary in different communications situations, but previous research suggests that all forms of effective support tend to incorporate variety, and provide choices in response to individual needs, preferences and situations of learners. As Moore (1989) previously put it, the need and exact character of learner support should vary "according to the educational level of the learners, the teacher's personality and philosophy, and other factors" (emphasis supplied). Interaction observed here addressed interpersonal needs and preferences, which can be regarded as being among these "other factors."

Also among the "other factors" available, thanks to the evolution and increasing familiarity of interactive technologies, is accessible and inexpensive or free supportive peer-to-peer interaction technologies of various kinds. As robust tools have become readily available to permit discretionary learner-learner interaction at the learners' discretion, there is now need to focus (as in this study) on describing the strategies engaged in when using these tools in online, courserelated, moderated interaction. Examination of the record of actual online interaction is a first step in understanding current uses of CMC, and assessing the communications tools (hardware and software) on which it is based.

The question posed by this study was whether evidence could be found in an online conference that participants actually took the time and made the effort to support each other when given the opportunity to interact, and what techniques were employed to provide supportive social interaction as well as the intercommunication of ideas and information. As in face-to-face interaction, the findings showed that the most common supportive activities focused on interpersonal recognition, inviting or extending dialogue, and demonstrating a sense of [n]etiquette. Greetings, signatures, statements making reference to others' comments, and openended questions constituted two-thirds of all online support behaviour; in so doing, this CMCbased interaction could be seen to imitate face-to-face normal communications in seminars and classrooms.

Some differences were noted which require further exploration. In the three groups overall, differences were found in the use of horizontal questions, referential statements, emoticons, and invitations to others to begin or continue participation. High- and low-support individuals differed in their uses of referential statements, greetings, signatures, horizontal questions, rhetorical questions, and humour. The bases for these differences was beyond the scope of this study, but explaining the conditions under which they seem to occur may be a next required step in research in this area.

\section{Conclusion}

Overall, the findings of this study suggest that participants used obvious interpersonal strategies to support each other: they asked open-ended or rhetorical questions; they referred to the contents of each others' comments; they invited others to join the conversation; they used "epistolary" techniques to create an ambiance in their correspondence similar to a private letter (greetings, signatures); and they used emoticons to clarify their tone (Fahy, 2002b).

Individually, there was considerable variation in uses of these conventions and communications techniques. As would be the case in other forms of social networking in learning environments, 
Fahy Indicators of Support in Online Interaction

everyone does not choose to engage in identical supportive behaviour. As in face-to-face situations, this study found that some individuals were more attentive to and involved in maintenance of the social network in which the purposive course-related communications occurred (Ridley and Avery, 1979).

The finding that students in three courses from two different distance programs and institutions used online interaction similarly in supportive ways, including going beyond academic requirements and expectations to motivate, demonstrate willingness to comment, and encourage others to continue interacting, is important. Supportive online social behaviour among participants (beyond basic civility) is usually not an explicit course requirement in most CMC learning environments (as it was not here). Some of the 13 indicators of support were not used equally by all participants (i.e., humour), and participants showed clear personal preferences in how they demonstrated support. But it is significant that virtually everyone found some way to engage in supportive interaction. (There was one exception among the 56 students, a male participant who posted only three times, and who included no supportive comments). One-quarter (25.9 per cent) of all interaction in these conferences was classified as supportive, a proportion which, though it must be tested against wider and larger conferencing samples, indicates the importance attached to the interpersonal in these online interactions.

\section{Attachment A}

1A - vertical questions: questions which assume a "correct" answer exists, if the right authority can be found to supply it. [“What are the categories in Bloom’s taxonomy?”]

1B - horizontal questions: accepts that there may not be one right answer; others are invited to help provide a plausible or alternate "answer," or to help shed more light on the question. [“What is good teaching?”]

2A - non-referential statements: contain no or very little self-revelation and usually do not invite response or dialogue; tone may be didactic; the main intent is to impart facts or information). ["Although our office has been in the business of providing program inservice and training workshops since its inception, it is new to the area of computer-mediated communications.”]

2B - referential statements: postings that make direct or indirect reference to elements of preceding statements. ["I want to add to \{name's \} point about the importance of context in assessing technologies.”]

3 - reflections: thoughts, judgments, opinions or information which are personal, or usually at least somewhat guarded or private; a tone of self-disclosure is suggested in the sharing process. ["I felt, as a teacher, that I had failed the most needy students - it's the reason I left teaching after ten years and lots of private tears.”]

4 - scaffolding and engaging: intended to initiate, continue, encourage or acknowledge interaction, and "warm" or personalize the discussion; the tone is friendly, even intimate; includes phatics and emoticons. ["Thanks for your brilliant description of the problems new teachers face - you could have been describing any one of us, I think.”] 
Fahy Indicators of Support in Online Interaction

5A - quotations and paraphrases: "Every tool carries with it the spirit by which it has been created."

5B - citations: "Werner Karl Heisenberg, Physics and Philosophy, 1958.”

\section{Attachment B}

\section{Support Indicators: Definitions and examples from the transcript}

1.

Acknowledgement

2. Agreement

3. Apology, selfcriticism

4. Closing

5. Emoticon

6. Horizontal questions

\section{Humour}

8. Inviting

\section{Referential statement}

Recognizing or acknowledging the helpfulness, ideas, comments, capabilities and experiences of other.

- "Interesting ideas."

- "Sounds like quite the experience you have."

Expressing agreement; connecting sympathetically with the views of another participant.

- "Like [name], I view advanced technologies as technologies that are not yet mainstream."

- "I agree that each media has a strength and weakness."

Any form of apology.

[See text.]

Ending the post with some closing summary or leave-taking convention.

- "Cheers."

- "All the best."

Using an emoticon in a post to provide tone.

- J

- (in my humble opinion ;-) ) [This includes a closing]

Questions which do not have a "correct" answer, but for which discussion might produce consensus or deeper understanding of the problem.

- "What do students 'understand' when they are taken into a computer lab, for example, before anything is "taught" with those computers at all?"

- "What is a 'learning technology' after all?"

Some effort at humour (may be self-deprecating or ironic).

- "Re: last message - see, I'm wide awake(?) and can even type my own name now."

- "I still want my 5\% - grinz."

Inviting agreement, sympathy or comment from others.

- "What do you think?"

- "Thoughts?"

Statement which makes specific reference to the content of a comment posted by another participant.

- "The impact you asked about is difficult to identify."

- "Very little teaching will take place over the "big pipe," as you called it." 
10. Rhetorical
question

11. Salutation

12. Signature

13. Thanks
Posing a rhetorical question.

- "But, hey, why force energy on a customer when they don't want it."

- "How can strategic plans survive?"

An expression of greeting, usually at the opening of the posting.

- "Hi, [name],"

- "[Name] and [name], ..."

- "Hi, all."

Ending a post with the writer's signature or a nickname.

Expressing thanks to another participant, or thankfulness for another's behaviour or views.

- "Thanks for getting me thinking about it."

- "Thanks for the information on the paper we discussed."

\section{Attachment C}

\section{Occurrence of Selected Support Indicators}

Table 4, Description of selected overall conferencing activity

\section{Table 5: Occurrence of TAT categories}

Table 6: Differences in support values, by course

\section{References}

Allen, J. (2002). Addressing Fragmentation: Building integrated services for student support. ERIC Documents: ED457431.

Brown, F. B., and Brown, Y. (1994). Distance education around the world. In Willis, B. (Ed). Distance education strategies and tools (p. 3-39). Englewood Cliffs: Educational Technology Publications.

Buderi, R. (1996). The invention that changed the world. New York: Simon and Schuster.

Burge, E. (2000). Using learning technologies: ideas for keeping one’s balance. Open Praxis 1, $17-20$.

Cannell, L. (1999). Review of Literature: Distance education association of theological schools. Unpublished paper.

Carnwell, R., and Harrington, C. (2001). Diagnosing student support needs for distance learning. Paper presented at the 41st Annual Meeting of the Association for Institutional Research. Long Beach, June 3-6. ERIC documents: ED457735.

Carrier, G., and Schofield, M. (1991). Student support and CMC in distance education. Canadian Journal of Educational Communication 20(1), 45 - 54. 
Commonwealth of Learning. (1993). Student Support Services: towards more responsive systems. Vancouver: Author.

DeSanctis, G., and Gallupe, R. B. (1987). A foundation for the study of group decision support systems. Management Science 33(5), 589 - 609.

Fahy, P. J., Crawford, G., and Ally, M. (2001). Patterns of interaction in a computer conference transcript. International Review of Research in Open and Distance Learning, 2(1). Retrieved July 8, 2002 from: http://www.irrodl.org/content/v2.1/fahy.html.

Fahy, P. J. (2002a). Use of linguistic qualifiers and intensifiers in a computer conference. The American Journal of Distance Education 16(1), 5 - 22.

Fahy, P. J. (2002b). Epistolary and expository interaction patterns in a computer conference transcript. Journal of Distance Education 17(1), 20 - 35.

Fahy, P. J. (2002c). Assessing critical thinking processes in a computer conference. Unpublished paper.

Feenberg, A. (1989). The written world: on the theory and practice of computer conferencing. In R. Mason and A. Kaye (Eds.) Mindweave ( p. 22-39). Toronto: Pergamon Press.

Garrison, D. R., Anderson, T., and Archer, W. (2000). Critical inquiry in a text-based environment: Computer conferencing in higher education. Internet and Higher Education, 11(2) (p. 1-14). Retrieved July 9, 2001, from: www.ualberta.ca/CMC

Garrison, D. R., Anderson, T., and Archer, W. (2001). Critical thinking, cognitive presence, and computer conferencing in distance education. The American Journal of Distance Education 15(1), $7-23$.

Garrison, D. R. (2002). Cognitive Presence for Effective Online Learning: The role of reflective inquiry, self-directed learning and metacognition. Presented to the Sloan Asynchronous Learning Network Invitational Workshop, September. Lake George, NY.

Herring, S. C. (1996). Two variants of an electronic message schema. In Susan C. Herring (Ed.) Computer-mediated communication (p. 81-106). Philadelphia, PA.: John Benjamins.

Johnson, M. N. (2001). Student use of computer-mediated communication in a distance education course. Hawaii WebNet World Conference in the WWW, October 24-30. ERIC documents: ED448723.

Juler, P. (1990). Promoting Interaction; Maintaining Independence: Swallowing the mixture. Open Learning 5(2), 24 - 33.

Lee, J. Y. (2000). Current Status of Learner Support in Distance Education: Emerging issues and future research agenda. Annual Proceedings of Selected Research and Development Papers, 23rd National Convention of the Association for Educational Communications and Technology, Denver, October 25-28. ERIC documents: ED 455815. 
Luedtke, C. B. (1999). Distance Education Programs in Texas Community and Technical Colleges: Assessing student support services in a virtual environment. Unpublished Master's thesis. Southwest Texas State University. ERIC documents: ED 438852.

McInnis-Rankin, E., and Brindley, J. (1986). Student support services. In I. Mugridge and D. Kaufman, D. (Eds.) Distance Education in Canada (p. 60-80). London: Croom Helm.

Moore, M. G. (1989). Three types of interaction. American Journal of Distance Education 3(2), 1 - 6. Retrieved November 9, 2001, from: http://www.ed.psu.edu/acsde/ajde/ed32.asp

Moore, M. G. (1991). Editorial: Distance education theory. The American Journal of Distance Education 5(3), 1 - 6.

Mugridge, I., and Kaufman, D. (1986). Distance Education in Canada. London: Croom Helm.

Purnell, K., Cuskelly, E., and Danaher, P. ( 1996). Improving distance education for university students: issues and experiences of students in cities and rural areas. Journal of Distance Education 11(2), 75 - 101.

Rezabek, R. J. (2002). A study of the motives, barriers and enablers affecting participation in adult distance education classes in an Iowa community college. Unpublished doctoral dissertation, University of Northern Iowa, 1999. ERIC documents: ED 463774.

Ridley, C., and Avery, A. (1979). Social network influence on the dyadic relationship. In R. Burgess and T. Huston (Eds.) Social exchange in developing relationships (p. 223-246). New York: Academic Press.

Robertshaw, M. (2000). Support groups in distance education. Knowledge Series. Commonwealth of Learning. Online. Retrieved May 13, 2002 from: http://www.col.org/Knowledge/ks_support.htm ERIC documents: ED 453379.

Saltiel, I. M., and Russo, C. S. (2001). Cohort programming and learning. Malabar, FL.: Krieger.

Sewart, D. (1993). Student support systems in distance education. In B. Scriven, R. Lundin and Y. Ryan (Eds.) Distance education for the twenty-first century. Selected papers from the 16th World Conference of the International Council for Distance Education, Thailand, November, 1992. Australia: International Council for Distance Education, Queensland University of Technology.

Simpson, O. (2000). Supporting students in open and distance learning. London: Kogan Page.

Stringer, R.A., and Uchenick, J. (1986). Strategy traps. Toronto: Lexington Books.

Tait, A. (1996). Conversation and community in open and distance learning. In J. Frankl and B. O’Reilly (Eds.) 1996 EDEN Conference: Lifelong learning, open learning, distance learning. Poitiers, France: European Distance Education Network, 12 - 16.

Tait, A. (2000). Planning student support for open and distance learning. Open Learning 15(3), $287-299$. 
Tobin, J. (1995). Evaluation and research frontiers: What do we need to know? In J. M. Roberts, and E. M. Keough (Eds.) Why the information highway? Lessons from open and distance learning (p. 201-225). Toronto: Trifolium Books Inc.

Walther, J. B. (1996). Computer-Mediated Communication: Impersonal, interpersonal and hyperpersonal interaction. Communication Research 20(1), 3 - 43. 